


\title{
THE WATER OF LIFE: WHERE DOES DESERT FOG COME FROM?
}

THE LACK OF RAINFALL IN DESERT ENVIRONMENTS MEANS THAT MANY PLANTS AND ANIMALS RELY ON FOG AND DEW TO PROVIDE THEIR WATER. BUT WHERE DOES THIS FOG COME FROM? AND WHAT WILL HAPPEN TO THESE ECOSYSTEMS AS THE CLIMATE CHANGES? PROFESSOR LIXIN WANG, A HYDROLOGIST AT INDIANA UNIVERSITY-PURDUE UNIVERSITY INDIANAPOLIS IN THE US, HAS BEEN LOOKING FOR THE ANSWERS TO THESE QUESTIONS

\section{TALK LIKE A HYDROLOGIST}

DEW - water droplets which condense onto cooled surfaces

DRYLANDS - areas where the rate of evaporation is much greater than the rate of precipitation, making water a scarce resource

FOG - closely-packed water droplets suspended in the air

HYDROLOGY - the study of how Earth's water moves, is stored and is used

ISOTOPES - forms of an element which have the same number of protons in their atomic nuclei, but different numbers of neutrons, meaning they have different masses

PRECIPITATION - water which falls to Earth e.g. rain, hail, snow

TRANSPIRATION - a process of water movement through plants before evaporation to the atmosphere from the plant surface
Covering over $40 \%$ of our planet's land surface, drylands are home to a third of the world's population. Including deserts (such as the Sahara in north Africa) and grasslands (such as the Great Plains in the US and Canada), key features of drylands include their low and unpredictable levels of rainfall, low levels of plant coverage and fragile ecosystems. To survive in such harsh conditions, plants and animals cannot rely solely on precipitation to provide their water. Instead, they have evolved methods to capture additional moisture contained in fog and dew. For example, certain beetle species endemic to the Namib Desert harvest the fog water using their wing scales and their unique body positions during fog events.

As Earth's climate warms, hydrologists predict that the water contained in drylands will become even scarcer, making the future of these ecosystems increasingly uncertain. Professor Lixin Wang, a hydrologist at Indiana University-Purdue University Indianapolis (IUPUI), studies the formation and origins of fog and dew in drylands around the world. His results are providing important insights into how these environments are changing, and how the organisms that live there will need to adapt to survive.

\section{HOW DO FOG AND DEW FORM?}

Even in drylands, the air contains water vapour Under the right conditions, this gaseous water can condense to form droplets of liquid water. Fog occurs when the atmosphere reaches saturation. Water droplets will form, suspended in the air, which can be intercepted by leaves or branches. Dew forms when water vapour condenses onto a cold surface, resulting in droplets forming directly on the ground or leaves. In both cases, plants and animals can take up the precious water in these droplets. In dryland environments, fog and dew usually form during the cool nights, before being evaporated once the sun rises.

The formation of fog and dew are incredibly important processes, but as Lixin explains, we still have much to learn about them. "Fog and dew sustain the survival of vegetation and other organisms in drylands," he says. "But their sources and the specific roles they play are not yet fully understood." As researchers seek to understand more about how drylands are being transformed by climate change, knowledge of these processes has never been more important. 

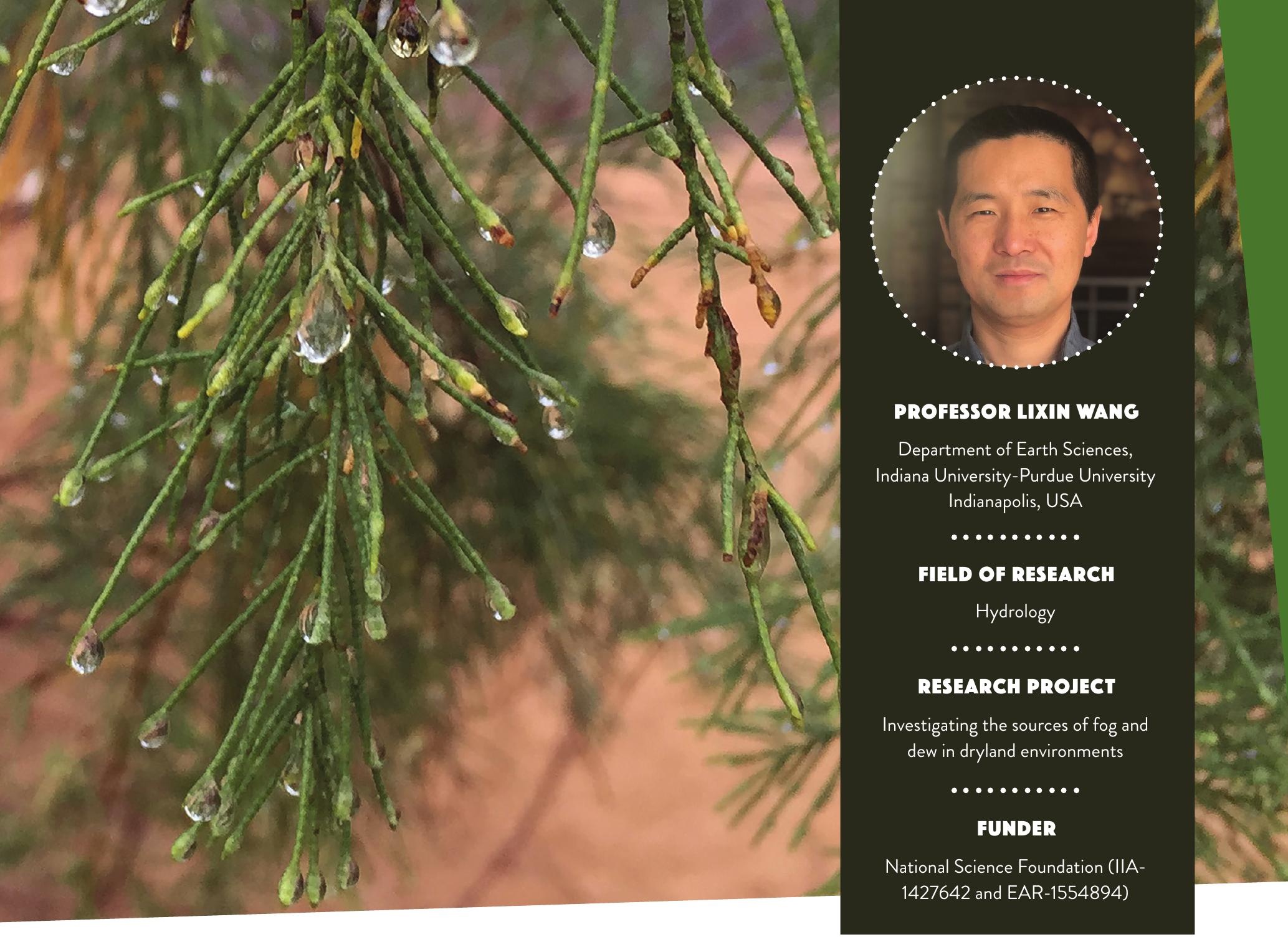

HOW DOES LIXIN COLLECT FOG AND DEW?

Unlike measuring precipitation, which can simply be collected in a container as it falls from the sky, measuring fog and dew is not so easy, and there are currently no standardised methods to do this. Lixin uses custom-designed fog and dew collectors, which he installs at his field sites in drylands around the world. His fog collector is a large net, which intercepts the suspended water droplets as they move through the air. As they collect on the large surface area provided by the fibres of the net, the droplets grow and eventually fall into a container below. His dew collector is simply a sheet of metal inclined at $45^{\circ}$. As the dew condenses onto the metal overnight, the droplets will run down the metal sheet and into a collection container.

Every morning, Lixin and his team must collect the fog and dew samples very early in the morning. "Evaporation will affect our measurements and the interpretation of our results," explains Lixin, "so we must collect the samples before the sun evaporates them. Also, some of our measurements, such as plant water potential, need to be taken before the sun rises, when plant transpiration is minimum." This involves some very early starts to the working day!
WHERE DOES THE FOG COME FROM?

In the Namib Desert in southern Africa, scientists have long assumed that the lifesustaining fog which appears many mornings is produced by moisture from the Atlantic Ocean. Lixin wanted to test if this was true.

To do this, he analysed the chemical composition of the water contained in the fog and dew samples that were collected in the Namib. "Water is made of hydrogen and oxygen atoms, and both elements have multiple naturally occurring isotope forms," explains Lixin. "Waters from difference sources, such as seawater and local groundwater, have small isotopic differences in their compositions." So, by measuring the mass of hydrogen and oxygen atoms in the water samples, Lixin could identify exactly where the moisture came from.

And, contrary to popular belief, the isotope analysis revealed that less than half of the desert's fog originates from the sea. Instead, much of the moisture comes from local water, contained in the soil.

WHAT IS THE FUTURE OF DRYLANDS? Lixin believes his results from the Namib Desert could have important implications

\section{PROFESSOR LIXIN WANG}

Department of Earth Sciences, Indiana University-Purdue University Indianapolis, USA

\section{FIELD OF RFSEARCH}

Hydrology

\section{RESEARCH PROJECT}

Investigating the sources of fog and dew in dryland environments

\section{FUNDER}

National Science Foundation (IIA1427642 and EAR-1554894) for our understanding of other dryland environments. As the climate changes, the Earth's drylands are predicted to become even drier, depleting their levels of groundwater. Since local water is an important potential source for fog, less groundwater will mean less fog, and therefore less water for plants and animals to drink.

Already, ecologists have observed that fogdependent beetles in the Namib Desert are migrating towards the coast, where fog is more plentiful than inland as it is supplemented by ocean moisture. "Fog and dew inputs will likely decrease due to a warming climate," Lixin says. "The more variable rainfall and decreased fog and dew inputs will negatively affect all living organisms in the desert."

Ultimately, with knowledge of where fog and dew originate, Lixin and his team are giving scientists a far clearer picture of the threats which dryland ecosystems face, and how they may transform in the coming decades. This understanding can help us to protect these fragile environments and enable the many people living in Earth's drylands to prepare for the approaching changes to their lives. 


\section{ABOUT HYDROLOGY}

Hydrology is a diverse field of science, which studies how water moves throughout Earth's land, ocean and atmosphere. Some hydrologists investigate how water resources can be better managed to improve sustainability, others develop new ways to protect people from floods and drought. Lixin specialises in 'ecohydrology,' a branch of hydrology that studies the interaction between vegetation and the water cycle.

\section{WHY IS HYDROLOGY SUCH AN} IMPORTANT FIELD TO STUDY?

Water is the single most important natural resource on Earth. Without water, no life could survive. Dryland environments are now home to 2.5 billion people, so understanding how water moves and is used in these regions is essential.

We need to know how ecosystems survive in such hostile, dry conditions in order to protect the natural environment and the communities living there. At the same time, too much water can also be deadly, with floods posing severe threats to communities and infrastructure around the world. Hydrologists seek to gain a better understanding of all natural and humaninfluenced processes related to water.

\section{WHAT DOES A HYDROLOGIST'S DAY INVOLVE?}

With such a range of topics studied by hydrologists, no two researchers will carry out the same tasks in their day-to-day lives. But hydrologists will often travel to exciting locations all around the world to conduct fieldwork or present results at conferences. For Lixin, a day in the field involves waking up very early to visit his fog and dew collectors before the sun rises.

"I still remember my first field trip to Africa, 15 years ago when I was a PhD student at the University of Virginia," Lixin says. "We did fieldwork in the Kalahari Desert in Botswana. Everything was new to me there - the landscape, the culture, the food. I just loved it. It's such a great feeling to sleep in a tent in the middle of nowhere, so close to nature."
WHAT CHALLENGES WILL FUTURE HYDROLOGISTS HAVE TO SOLVE?

Climate change is perhaps the greatest challenge that humans have ever faced, and the work of hydrologists is crucial to understanding how our planet will change in the coming decades. For Lixin, this will involve investigating how more unpredictable rainfall and the unsustainable use of groundwater will impact fragile dryland ecosystems.

Future hydrologists will study the changing water availability in all ecosystems, as a result of climate change and human extraction. They will examine how variations in the water cycle will influence our cities, while trying to find solutions to the increasing presence of floods and droughts. And they will encourage sustainable water management in communities around the world, ensuring that this most precious resource is available for everyone.

Ultimately, the next generation of hydrologists will be at the front line of global efforts to understand and adapt to a changing world.

\section{EXPLORF A CARAER IN HYDROLOGY}

- As such a wide and varied field, you could become an academic hydrologist like Lixin, studying whichever aspect of hydrology most interests you. Or you could apply your knowledge to roles in sustainable water management or flood engineering.

\section{- The American Geophysical Union has} useful resources for school students: www.agu.org/Share-and-Advocate/Share/ Community/K-12-Education-Resources

\section{Lixin gives talks and runs tours of his} lab for high school students, as well as organising training courses for teachers: earthsciences.iupui.edu/ /xwang/Lixin_

Wang/Summer_Training.html

- "Find opportunities to get some research experience early," advises Lixin. Contact professors, who will be happy to talk about their research and provide advice. Lixin's contact details can be found through his webpage:

science.iupui.edu/people-directoryl people/wang-lixin.html






\section{HOW DID LIXIN BECOME A HYDROLOGIST?}

The city I grew up in is surrounded by mountains and a large river runs through it. Since I was very young, I loved to climb mountains, explore caves, and catch fish, birds and insects to raise them at home. Despite my mom's disapproval, I managed to maintain a small 'zoo' at home! I was fascinated by living organisms and liked to study them. In middle school, I became interested in science fiction and I even wrote a couple of science fiction stories - they never got published. I think my interests in living organisms and science fiction triggered my passion to explore unknown things and do research.

\section{The name my parents gave me means} "being creative" in Chinese. My father has been always telling me do things creatively, I think this greatly influences my career choices.
I really enjoy the intellectual freedom and time flexibility of being a scientist. Although I work a lot, it's often my own decision how long I work, when I work and what I work on.

I have an undergraduate and master's degree in biology and a PhD in environmental science. My PhD research was on African savannas, a dryland. Water is a key player in such systems and that made me interested in hydrology. It was a natural transition from biology to ecohydrology as I look at the water cycle through the lens of biology and vegetation. There were new skills I needed to learn for the transition, but being a scientist, you always need to learn new things, so this was not a real barrier for me.

I enjoy travelling and always want to see new places. I have been to 49 states in the US and have been to all six habitable continents. I would love to visit Antarctica before catastrophic changes occur in West Antarctica, which I really hope do not happen in my lifetime.

I truly enjoy what I am doing every day. In the future, I think I will continue doing what I do now, trying to do better in every aspect.

\section{LIXIN'S TOP TIPS}

$$
01 \text { Find your passion. }
$$

02 Try to improve your writing skills early on.

03 Be persistent.

\section{MEET KUDZAI FARAI KASEKK}

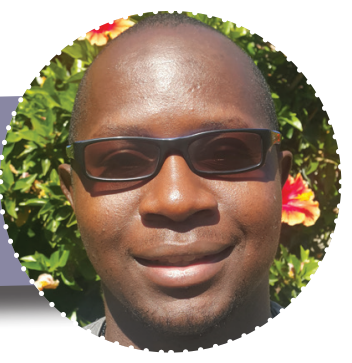

Dr Kudzai Farai Kaseke is a postdoctoral researcher at the University of California, Santa Barbara in the US. Following an undergraduate degree in agriculture and soil science from the University of Zimbabwe and a master's in conservation ecology from the University of Stellenbosch, Farai completed a PhD at IUPUI where he was supervised by Lixin.

\section{My undergraduate studies gave me a} broad understanding of environmental sciences and sharpened my laboratory technical skills. My master's introduced me to dryland ecosystems and developed my research and writing skills. These skills were the foundation of my work with Dr Wang, who then introduced me to the fascinating world of isotopes. This elevated my research expertise such that we could tackle and answer questions that had not been answered before.
My participation in the study of fog and dew in dryland environments involved data collection during field work, laboratory analysis, data analysis, writing and publishing scientific papers and disseminating our results. Highlights included collaborating with international institutions, international travels and presenting our work at conferences.

As an early career scientist, I am proud to have already collaborated at the international stage. I have also published 20 scientific papers. These have helped advance my career and some have garnered wide media attention meaning our work is reaching a much larger audience.

In the future I hope to continue publishing scientific articles, expand to policy issues and secure my own funding. At the same time, I would like to encourage and mentor young people of colour into the environmental sciences to show this as a viable career pathway for them.

\section{FARAIS TOP TIPS}

01 Get a broad understanding of environmental science before specialising, which will give you versatile knowledge of multiple fields.

02 Learn to code because this is becoming an essential skill across all disciplines - getting comfortable with coding while you are in school will make your progress easier.

03 Talk to as many scientists or professors as you can to find out more about opportunities. 